\title{
The Effects of Trader Type on Market Maker's Effective Bid-Ask Spread
}

\author{
Jang Hyung Cho \\ San Jose State University \\ Artem Meshcheryakov \\ San Jose State University \\ Janis K. Zaima \\ Menlo College
}

Using intraday trading data on U.S. Treasury note futures, we analyze the effects of trader type on market maker's effective bid-ask spread. We find that market makers tend to experience losses when price uncertainty increases in the market, even though market maker's effective BASs are positive on average. When the overall trading volume increases, the effects of economies of scale and competition between market makers and exchange member institutions cause market makers to narrow the effective bid-ask spread. However, when off-exchange traders increase their trading volume, market makers respond by lowering their buy prices and increasing sell prices, thereby widening the effective bid-ask spread. The results reveal that market makers protect themselves against risk when trading with off-exchange traders.

Keywords: bid-ask spread, market making, futures, type of trader, volume

\section{INTRODUCTION}

Market makers provide liquidity in the market for the service of immediate trading (Demsetz, 1968), and charge the bid-ask spread (BAS) for that. These BASs are affected by three factors: order processing cost, inventory holding cost and adverse selection cost. ${ }^{1}$ Past studies show that these costs are linked to price volatility and trading volume. In particular, the inventory holding cost increases when price volatility and trading volume cause the market makers' portfolios to deviate from their optimal levels (Stoll, 1978). Additionally, the adverse selection cost arises when the market makers trade with informed traders, and this asymmetric information cost is positively correlated with both price volatility and trading volume, as market makers widen their BASs to avoid losses caused by trading with informed traders (Bagehot, 1971; Copeland and Galai, 1983). Additionally, a study by Easley and O'Hara (1987) confirm that market makers use trading volume as a signal of an information event. Further, Lee et al. (1993) and Wang et al. (1994) present empirical evidence that trading volume rises abnormally during information events, and results in the widening of BASs.

While past studies have shown that trading volume includes the effects of economies of scale (McInish and Wood, 1992) and competition in market making (Demsetz, 1968) as well as risk components (Lee et al., 1993; Wang et al., 1994), they did not examine the type of traders that may elevate risk via their trading 
volume. Nor we are aware of any study, that analyzed market makers' reaction to the perceived risk of trading with different type of traders.

The purpose of this paper is to examine how different type of traders affect market maker's effective bid-ask spread (BAS). Moreover, we analyze the inner process of market making in managing their buy and sell prices to protect against risk. For our analysis, we use intraday U.S. interest rate futures data which disaggregate trading volume by customer trade indicator (CTI).

Results show that BASs (sell price - buy price) of exchange member institutions (CTI2) as well as of the market makers (CTI1) are positive on average, implying that both types of traders (CTI1 and CTI2) competitively provide liquidity in the market. Hence, when they increase their trading volumes, the BAS consistently declines. Meanwhile, off-exchange traders (CTI4) aggressively demand liquidity. Not only are the BASs of the off-exchange traders negative i.e., buy prices $>$ sell prices, on average, but the size of the market makers' effective BASs increases when off-exchange traders raise their trading volume. Moreover, results show that they (CTI4) use a momentum trading strategy which exacerbates price volatility.

Based on the methodology presented in Harris (2003), we split BAS into the half spreads from each buy and sell price to determine the inner process with which the market makers widen their BASs when trading with the off-exchange traders. This study is the first empirical study that demonstrates that market makers lower their buy prices and increase sell prices when the off-exchange traders increase buy and sell volume equally.

The article is organized as following: in Section 2 we provide a literature review and develop testable hypotheses. In Sections 3 and 4 we describe the data and the methodology used in our study, respectively. In Section 5 we present empirical results and in Section 6 we conclude.

\section{LITERATURE REVIEW AND TESTABLE HYPOTHESIS}

\section{Effects of Trading Activities on Bid-Ask Spread}

The literature on the bid-ask spread documents that volatility and trading activity significantly affect the components of the bid-ask spread. While the positive association between volatility and the bid-ask spread (BAS) is clear, the relationship between trading volume and the BAS is dependent on the driving factors behind the trading volume.

According to previous research, a significant portion of order processing costs, such as exchange and clearing fees, bookkeeping and back office costs are fixed. Therefore, keeping everything else constant, the average order processing cost should decline when trading activity increases due to the economies of scale. McInish and Wood (1992) using NYSE stock data in the first six months of 1989 report the effects of economies of scale on BAS in that the BAS decreases when trading volume per transaction rises. Ding (1999) uses the foreign exchange futures data in 1990 and finds similar relationship between economies of scale and trading costs. His results demonstrate that a greater number of transactions is associated with smaller BAS.

Demsetz (1968) observes that competition in market making lowers BAS. He states that market makers would like to acquire inventory at low prices and resell at high prices very rapidly. However, with competitive forces at work, the stronger these forces are, the closer the markups will be to the cost of waiting and carrying inventory. His results with 192 NYSE stocks show that the number of transactions per day is inversely related to BAS. McInish and Wood (1992) report that BASs are narrower at the NYSE than other U.S. stock exchanges due to greater competition in market making. ${ }^{2}$

The above studies show that BAS narrows in response to the increase in trading activity due to the economies of scale in trading costs and the effects of competition in market making. On the other hand, the increase in trading activity can also cause the BAS to widen if it elevates the adverse selection risk and the inventory holding risk.

Bagehot (1971) mentions that market makers lose to informed traders and hence widen BAS to protect themselves. Similarly, Copeland and Galai (1983) and Glosten and Milgrom (1985) argue that including the adverse selection component in BAS protects market makers from information asymmetry. ${ }^{3}$ Harris (2003, pp. 285) also states that the market makers sometimes lose when the price volatility becomes 
unexpectedly high. Accordingly, French and Roll (1986) find that information is the main factor for high volatility.

Given that a high volatility and trading with informed traders can expose market makers to losses, the market microstructure literature finds that market makers may sense the adverse selection risk via increased trading activities. Easley and O'Hara (1987) note that informed traders prefer to trade in large volumes to take advantage of information. Lee et al. (1993) use 230 NYSE firms in 1988 to examine the effects of information on trading volume, BAS and market depth. They find that high trading volume measured at 30-minute intervals is associated with wide BAS. In particular, trading volume surges and BASs increase during earnings announcements, demonstrating that the increase in trading volume reflects information about earnings announcements. Wang et al. (1994) find that in the futures market, the trading volume per transaction is positively related to the market makers' BAS during the crisis of 1987 (Oct. 14 - Oct. 26) although it does not demonstrate same relationship in the pre-crisis period (Sept. 16 - Oct. 13). That is, trading volume grew bigger when there was unusual information in the market and the BAS widened in response.

\section{Trader Type and Volatility}

According to the Commodity Futures Trading Commission (CFTC), futures traders are classified into four groups by customer trade indicator (CTI): CTI1, CTI2, CTI3 and CTI4. The CTI1 traders are individual market makers who trade on their own accounts. The CTI2 traders are clearing member institutions. The orders of non-clearing member firms, previously coded as CTI4, were reclassified as CTI2 in 2005. The CTI3 traders are the traders who execute orders for other exchange members. The CTI4 traders are offexchange traders, such as individual traders and any other unclassified small institutional traders. Prior studies find that in the U.S. futures market the off-exchange traders (CTI4) are aggressive and increase volatility. Daigler and Wiley (1999) use various financial futures data from 1986 to 1988 and find that the trading volume of off-exchange traders exhibits a positive correlation with volatility. Meanwhile, the trading volume of exchange clearing members (CTI2) is often inversely related to volatility. Avramov et al. (2006) use TAQ stock market data from 1993 to 1998 to examine the effects of trading strategy on volatility. They find that momentum strategy increases volatility whereas contrarian strategy reduces volatility. ${ }^{4}$ Chou, Wang and Wang (2015), using Taiwan futures data, also find that momentum trades are positively correlated with volatility whereas contrarian traders are negatively correlated with volatility.

Since momentum trades increase volatility as shown in Avramov et al. (2006) and Chou et al. (2015), it is expected that the off-exchange (CTI4) traders, whose trading volume is positively correlated with volatility (Daigler and Wiley, 1999), use momentum strategy. In that regard, Cho et al. (2019) and Llorente and Wang (2020) show that the off-exchange traders, indeed, use the momentum strategy and drive up volatility in the interest rate and corn futures markets, respectively. They also find that the exchange clearing institutions (CTI2) use the contrarian strategy and lower volatility. In addition, both of their results show that the CTI4 momentum trades dominate CTI2 contrarian trades and systematically pressure prices to change to the direction of their (CTI4) trades. The market makers (CTI1) are weakly contrarian, i.e., the market makers' net buy volumes are weakly inversely related to returns.

\section{Contributions and Testable Hypotheses}

We make unique contributions to the literature in two ways. First, unlike prior studies, we examine the effects of trading volume on the market maker's effective BAS by type of trader. It is expected that market makers in the futures markets tend to widen bid-ask spread (BAS) when trading with aggressive traders. According to Daigler and Wiley (1999), Cho et al. (2019) and Llorente and Wang (2020), the off-exchange traders (CTI4) are aggressive and tend to increase volatility whereas the institutional traders (CTI2) usually lower volatility. To stay competitive, the market makers (CTI1) need to decrease the BAS. Therefore, the first hypothesis states as follows. 
Hypothesis 1 [H1]: The increase in trading volume by market makers (CTI1) and institutional traders (CTI2) causes the market maker's effective bid-ask spread (BAS) to narrow, whereas that of off-exchange traders (CTI4) causes the BAS to widen.

On the other hand, if the off-exchange (CTI4) traders are noisy liquidity traders and hence lack consensus in their trades (or they do not bring any new information to the market), then higher volume of CTI4 traders may correspond to the arrival of public limit orders on both sides of the bid-ask spread (Harris and Raviv, 1993; Lee et al., 1993). In this case, the rise in trading volume of the CTI4 traders will result in the increase of liquidity and hence decrease BAS.

Our second contribution is that unlike prior studies, we separately investigate the market makers' (CTI1) buy and sell orders. Massimb and Phelps (1994) specify that on GLOBEX electronic futures markets, it is possible for the parties involved in the transactions to see with whom they are trading. Hence, when market makers trade with non-aggressive traders (CTI1 and CTI2), they try to compete in market making, and thus we expect a narrow effective BAS. Specifically, it is expected that market makers will increase the buy price and decrease the sell price in response to the increased buying volume and selling volume generated by CTI1 and CTI2 market participants, respectively. However, when market makers trade with more aggressive traders (CTI4), they prioritize risk management over competition, and thus we expect the effective BAS to widen. Specifically, market makers will decrease the buy price and increase the sell price in response to the increased trading volume generated by the off-exchange traders (CTI4) respectively. Based on these considerations, our second hypothesis is shown below.

Hypothesis 2 [H2]: Market maker's half effective bid-spread widens when market makers (CTI1) trade with the off-exchange traders (CTI4). Market maker's half effective ask-spread narrows when market makers trade with the off-exchange traders (CTI4).

\section{DATA AND VARIABLES DEFINITIONS}

\section{Sample Data}

We use electronically traded nearby interest rate futures data from The Chicago Board of Trade (CBOT) Liquidity Data Bank (LDB) on the 2-year T-note futures, 5-year T-note futures and 10-year T-note futures from September 2003 to 2006. The LDB is the only intraday dataset which disaggregate the futures transactions by customer trade indicator (CTI). ${ }^{5}$ The dataset contains prices traded for each 15 -minute time interval and the associated buy and sell volumes. We use 30-minute intraday intervals as done in prior studies (McInish and Wood, 1992, Lee et al. 1993; Ding, 1999). The buy and sell trading volume in the dataset is reported by trader type (CTI1, CTI2, CTI3, CTI4). The intraday time period used in this study is from 7:30 AM to 2:00 PM CST, similar to Ding's study (1999). Figure 1 shows that trading is very inactive during the overnight session, especially for market makers (CTI1). The futures contracts are actively traded until two to three weeks before their expiration. When the trading volume decreases significantly, the observations are not used in the analysis for statistical purposes.

Table 1 provides yearly averages of futures contracts and volume shares by type of trader. Data show that the overall volume of the 2-Year T-note futures is smaller than the other futures. The total number of contracts commonly increases in time, representing greater volume in later years. The volume share of CTI2 institutional traders has risen significantly from 2005 due to the reclassification of non-clearing member firms, previously coded as CTI4, into CTI2. For the same reason, the volume share of CTI4 individual traders has fallen since the 2005 reclassification. The volume share of the CTI3 traders accounts only for about $0.3 \%$ to $4.3 \%$. Hence, they are excluded from the analysis. 


\section{FIGURE 1}

\section{PATTERN OF INTRADAY FUTURES TRADES}

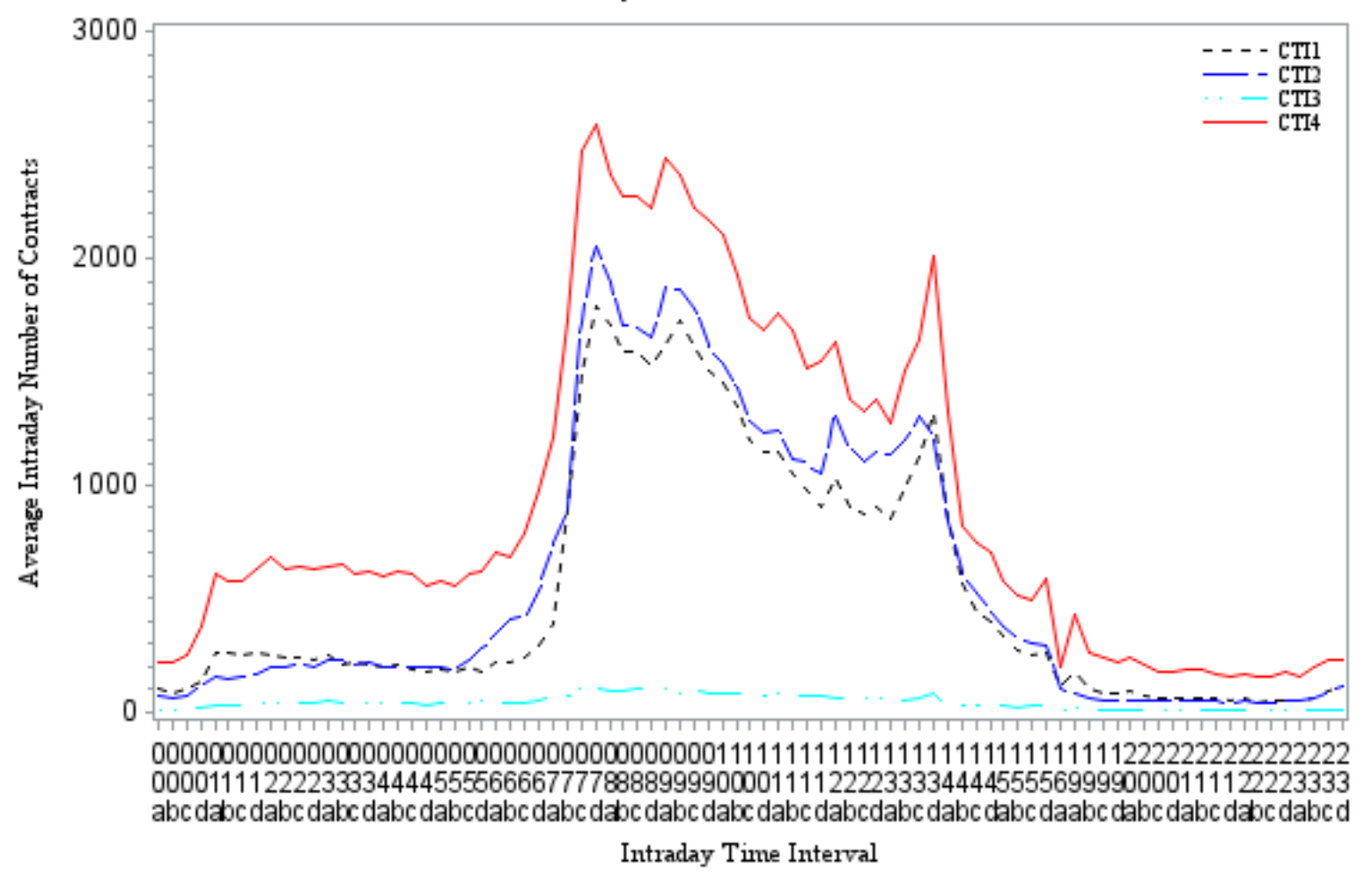

Figure 1 shows the average intraday contracts by type of trader in 2004 for the 10-year T-note futures as an illustration. The same pattern appears for other T-note futures. Trading becomes active from 7:30 AM (denoted by 07c) until 2:00 PM (denoted by 14d). The CTI1 market makers' trading is inactive outside the intraday sample period. Hence, the estimation of market makers' intraday bid-ask spread is statistically unavailable during the overnight trading.

TABLE 1

TREND OF FUTURES CONTRACTS AND VOLUME SHARES

\begin{tabular}{|c|c|c|c|c|c|}
\hline & Total Contracts & S1 & S2 & S3 & S4 \\
\hline \multicolumn{3}{|c|}{ Panel a: 2-Year T-note futures } & & & \\
\hline 2003 & 274,200 & 13.6 & 13.0 & 4.3 & 69.1 \\
\hline 2004 & $2,920,875$ & 22.1 & 9.9 & 1.0 & 66.9 \\
\hline 2005 & $8,325,362$ & 17.8 & 37.7 & 0.3 & 44.2 \\
\hline 2006 & $14,919,899$ & 20.8 & 46.4 & 0.4 & 32.4 \\
\hline \multicolumn{7}{|c|}{ Panel b: 5-Year T-note futures } & & & \\
\hline 2003 & $9,500,085$ & 25.0 & 32.6 & 2.7 & 39.7 \\
\hline 2004 & $46,824,189$ & 27.8 & 30.9 & 1.1 & 40.2 \\
\hline 2005 & $58,559,340$ & 22.1 & 53.7 & 0.4 & 23.9 \\
\hline 2006 & $59,420,237$ & 19.9 & 54.5 & 0.3 & 25.3 \\
\hline
\end{tabular}




\begin{tabular}{|c|c|c|c|c|c|}
\hline \multicolumn{3}{|c|}{ Panel c: 10-Year T-note futures } & & & \\
\hline 2003 & $20,959,755$ & 23.3 & 32.5 & 3.7 & 40.5 \\
\hline 2004 & $96,330,471$ & 27.0 & 30.4 & 1.7 & 40.9 \\
\hline 2005 & $103,734,767$ & 25.7 & 44.5 & 0.5 & 29.3 \\
\hline 2006 & $124,188,849$ & 21.0 & 50.5 & 0.4 & 28.1 \\
\hline
\end{tabular}

Table 1 provides yearly averages of futures contracts and volume share by type of trader. Total contracts represent the total number of contracts traded by all types of traders (CTI1, CTI2, CTI3 and CTI4) during the intraday sample period. The intraday time periods used in this study is from 7:30 AM to 2:00 PM as done in Ding (1999). The volume share $(S k)$ represents the ratio of volume of CTIk to total volume, where $\mathrm{k}=1,2,3$ and 4 .

\section{Variables Definitions}

Electronic futures markets are order driven markets in which bid-ask spreads are not directly set by market makers but by all public limit orders. Moreover, market makers in futures markets are not bound to post bid and ask quotes (Laux and Senchak, 1992; Raman et al., 2014). Therefore, we determine the market maker's effective bid-ask spread (BAS) with prices and only associated market makers' trading volume data. Harris (2003, pp. 422-426) describes a specified price benchmark method to estimate transaction costs from the perspectives of liquidity demanders and defines the volume weighted average price (VWAP) as the most common benchmark price. Refer to the Appendix for details about VWAP. Specifically,

Transaction cost for a purchase $=$ liquidity demander's buy price - VWAP

Transaction cost for a sale $=$ VWAP - liquidity demander's sell price

Since a liquidity demander's buy (sell) price corresponds to a market maker's sell (buy) price, the transaction cost for a purchase (sale) is equivalent to the market maker's half spread for a sale (purchase) in the opposite signed value. Hence, the market maker's effective bid-spread, ask-spread and BAS are determined as follows:

Bid spread $(\mathrm{BS})=\mathrm{VWAP}-$ market maker's buy price

$=(-1) \times$ Transaction cost for a sale

Ask spread $(\mathrm{AS})=$ market maker's sell price - VWAP

$=(-1) \times$ Transaction cost for a purchase

Bid-ask spread $(\mathrm{BAS})=\mathrm{BS}+\mathrm{AS}=$ market maker's sell price - market maker's buy price

Note that the VWAP is determined by overall transactions across all types of traders. But, the buy and sell prices in (3) and (4) represent the market makers' volume-weighted buy and sell prices for each 30minute interval. Hence, the values of BS and AS are determined by only the market makers (CTI1).

Also, note that the benchmark price in the half bid-spread (BS) and half ask-spread (AS) is not equal to half of the market makers' buy and sell prices, but to the VWAP. As a result, the sizes of the BS and AS can differ. In other words, if market makers' reactions when filling their counterparty's sell orders is greater than when filling their counterparty's buy orders, then their bid spread will be greater than their ask spread.

The trading volume is determined by the square root of (BUY + SELL)/2 for each 30-minute interval, where BUY and SELL stands for the total buy and sell number of futures contracts. The total volume for each intraday interval is the square root of total futures contracts across type of trader as shown in (7). Specifically, 
Volume $_{i t k}=\sqrt{\frac{B U Y_{i t k}+S E L L_{i t k}}{2}}$

Volume $_{i t}=\sqrt{\sum_{k}\left(\frac{B U Y_{i t k}+S E L L_{i t k}}{2}\right)}$

where $i, \mathrm{t}$, and $\mathrm{k}$ are the indexes for the 30 -minute intraday $(\mathrm{i}=1, \ldots, 13)$, day $(\mathrm{t}=1, \ldots, \mathrm{T})$ and type of trader $(\mathrm{k}=\mathrm{CTI} 1, \mathrm{CTI} 2, \mathrm{CTI} 3, \mathrm{CTI} 4)$. The volatility is the volume-weighted price volatility ("VWVolat" hereafter) for each 30-minute interval as defined in (8).

Volatility $_{i t}=\sqrt{\sum_{j}\left(v_{j i t}\left(P_{j i t}-V W A P_{i t}\right)^{2}\right)}$

where $j$ is the index for price at which Volume ${ }_{j i t}$ has occurred. $v_{j i t}$ is the volume weight on $P_{j i t}$ as defined in (A1). The intraday volatility in (8) is equivalent to the conventional definition of standard deviation except that it uses the volume weight as probability. When the market is active, prices tend to change more often, and the difference between high and low prices grows. Hence, we also use the high-low volatility ("HiLoVolat" hereafter) and the number of prices ("NPrice" hereafter) where transactions have occurred for each 30-minute interval along with the VWVolat.

\section{METHODOLOGIES}

Market makers try to have a wide effective BAS in order to protect their positions when volatility increases, showing a positive relationship between BAS and volatility. However, for an empirical analysis it is important to recognize that market maker's effective BAS can be negative when volatility rises and the price drops (rises) before they can sell (buy). In this case, the relationship between BAS and volatility is negative. However, their overall effective BAS must be positive in order for them to be profitable and stay in business. Therefore, we determine the values of the intraday effective BAS based on equation (5) and sort them in ascending order. The sorted BASs are divided in deciles as shown in Figure 2 with the first decile containing the lowest BASs. The BAS will take the largest negative average of BASs in the first decile and turn positive in the later deciles. The measures of volatility (VWVolat, HiLoVolat, NPrice) are determined along with the BAS for each intraday interval. We analyze if the first decile has the largest negative effective BAS with a higher volatility. However, the overall average BAS across all deciles is expected to be positive. 
FIGURE 2

MARKET MAKER'S EFFECTIVE BID-ASK SPREAD IN DECILES

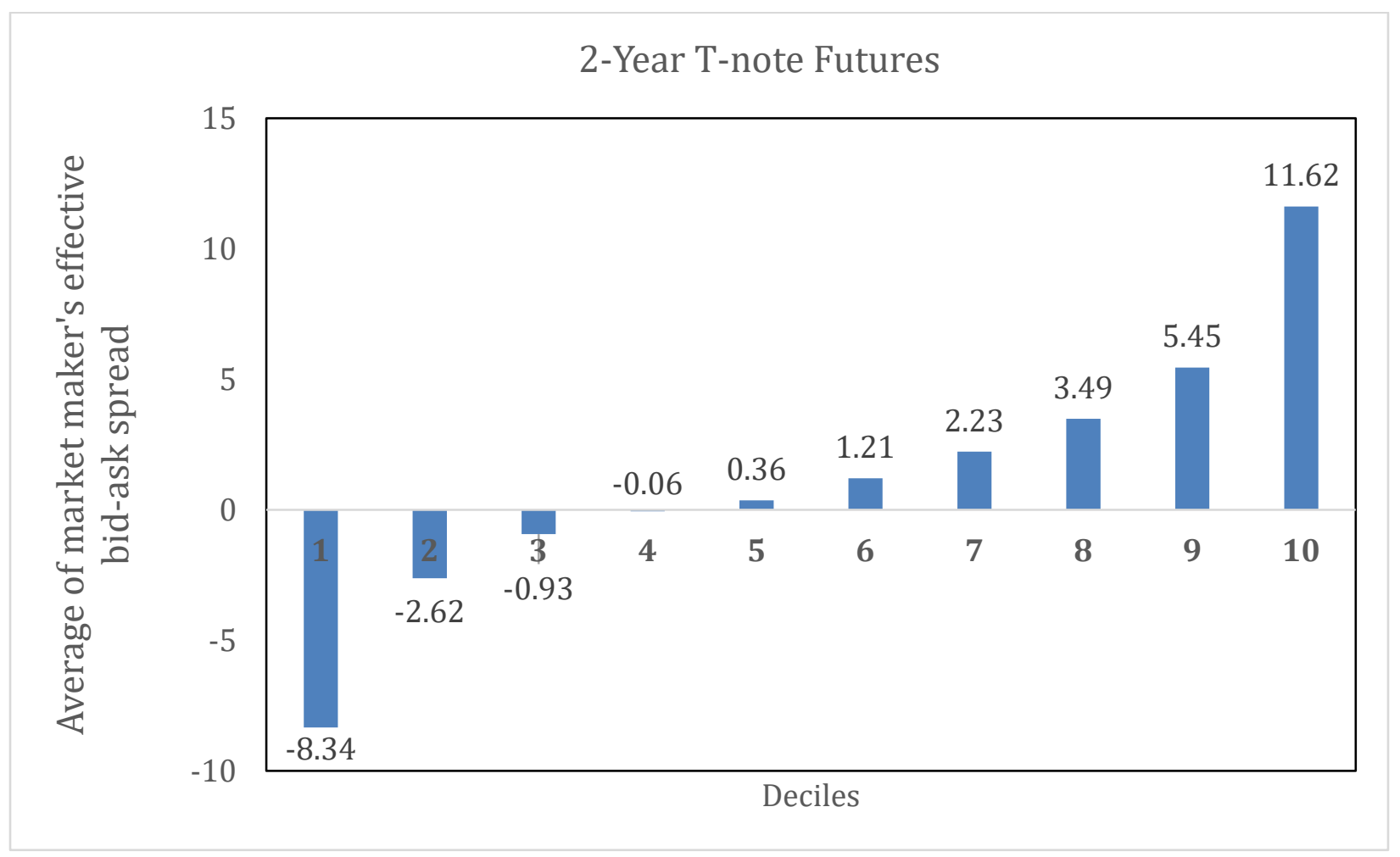

The estimates of intraday BAS in (5) are sorted in an ascending order and grouped in deciles. Since market makers sometimes realize negative bid-ask spreads (BASs), the first decile has the largest negative average of BASs. The largest positive average of BASs belongs to the tenth decile.

For the hypothesis test [H1] of the effects of trading volume by trader type on the market maker's effective spread, we first analyze the effect of the aggregate total volume on BAS. The main regression equation that we use about market maker's effective BAS in (9-1) is similar to the model in McInish and Wood (1992) and Ding (1999) that include trading volume and volatility with dummy variables. Frank and Garcia (2011) take into consideration the endogeneity of volume and volatility in determining BAS. Accordingly, we employ structural equations in (9-1), (9-2) and (9-3) estimated by two stage linear squares (2SLS). The models in (9-2) and (9-3) show the simultaneous relation between volume and volatility. ${ }^{6} \mathrm{We}$ perform Durbin-Wu-Hausman endogeneity test to examine if volume and volatility are endogenous in determining market makers' BAS. If they are endogenous, then 2SLS is preferred to OLS. ${ }^{7}$

$$
\begin{gathered}
\begin{aligned}
\text { BAS }_{i t}=b_{10} & +b_{11} \text { Volume }_{i t}+b_{12} \text { Volatility }_{i t}+b_{13} \text { TTM }_{t}+b_{14} \text { TTM }_{t}^{2} \\
& + \text { Intraday }_{\text {weekday and year dummies }}+e_{i t}
\end{aligned} \\
\text { Volatility }_{i t}=b_{20}+b_{21} \text { Volume }_{i t}+b_{22} \text { Volatility }_{(i-1) t}+\text { Intraday dummies }+e_{i t} \\
\text { Volume }_{i t}=b_{30}+b_{31} \text { Volatility }_{i t}+b_{32} \text { Volume }_{(i-1) t}+\text { Year dummies }+e_{i t}
\end{gathered}
$$

where Volume $_{i t}$ is the square root of the number of futures contracts as defined in (7) i.e., $\sqrt{\left(B U Y_{i t}+S E L L_{i t}\right) / 2}$, where $B U Y_{i t}$ and $S E L L_{i t}$ stands for the total buy and sell contracts during each intraday interval. Volatility $y_{i t}$ is the volume-weighted average volatility as defined in (8). $T T M_{t}$ is the time to maturity. For example, if there are 50 days to maturity, then its value is 50 . The 30 -minute intraday 
intervals are denoted by subscript $i$, with $i=1, \ldots, 13$. For example, if the observation belongs to the first 30-minute time interval from 7:30 AM to 8:00 AM then i is assigned the value of 1, and zero otherwise. Similarly, if the observation belongs to the last 30-minute time or from 1:30 PM to 2:00 PM then i is assigned the value of $13 .{ }^{8}$ Prior studies document that the sign of the coefficient on Volume $i t$ tend to be negative if the economies of scale and competition in market making prevail (Demsetz, 1968; McInish and Wood, 1992; Ding, 1999) and the sign of the coefficient turns positive when the risk of adverse selection is significant (Lee et al., 1993; Wang et al., 1994). The sign of the coefficient on $T T M_{t}$ is expected to be negative i.e., $b_{13}<0$, because the BAS widens as the volatility rises and volume decreases when maturity nears as reported in previous studies (Cheng et al., 2005). The squared value $T T M_{t}^{2}$ is also included to consider potential nonlinear effect of TTM.

We disaggregate the trading volume by type of trader and employ the following 2SLS regression models to examine how the trader type affects the relation between trading volume and the market maker's effective BAS. ${ }^{9}$

$$
\begin{aligned}
& B A S_{i t}=b_{10}+b_{11} \text { Volume }_{i t}+b_{12} \text { Volume }_{i t}+b_{13} \text { Volume }_{\text {it }} \times A F T E R+\mathrm{b}_{14} \text { Volume }_{i t} \\
& +b_{15} \text { Volatility }_{i t}+b_{16} \text { TTM }_{t}+b_{17} \text { TTM }_{t}^{2}+\text { Dummy Variables }+e_{t} \text {. } \\
& \text { Volatility }_{i t}=b_{20}+b_{21} \text { Volume }_{i t}+b_{22} \text { Volume }_{i t}+b_{23} \text { Volume }_{i t} \\
& +b_{24} \text { Volatility }_{(i-1) t}+\text { Intraday dummies }+e_{i t} \text {. } \\
& \text { Volume } 1_{i t}=b_{30}+b_{31} \text { Volume }_{i t}+b_{32} \text { Volume }_{i t}+b_{33} \text { Volatility }_{i t} \\
& +b_{34} \text { Volume }_{(i-1) t}+\text { Year dummies }+e_{i t} \text {. } \\
& \text { Volume } 2_{i t}=b_{40}+b_{41} \text { Volume }_{i t}+b_{42} \text { Volume }_{i t}+b_{43} \text { Volatility }_{i t} \\
& +b_{44} \text { Volume }_{(i-1) t}+\text { Year dummies }+e_{i t} \text {. } \\
& \text { Volume }_{i t}=b_{50}+b_{51} \text { Volume }_{i t}+b_{52} \text { Volume }_{i t}+b_{53} \text { Volatility }_{i t} \\
& +b_{54} \text { Volume }_{(i-1) t}+\text { Year dummies }+e_{i t} \text {. }
\end{aligned}
$$

where Volume $k_{i t}$, with $\mathrm{k}=\mathrm{CTI} 1$, CTI2 and CTI4, represents the volume traded by CTI $\mathrm{k}$. AFTER is a dummy to distinguish time periods before and after the reclassification of non-clearing member institutional traders from CTI4 into CTI2. Specifically, we set AFTER to 1, if the observation belongs to the period from 2005 and 2006 and zero otherwise. As shown in Table 1, the volume share (S2) of CTI2 traders jumped up from 2005 in all futures contracts. Hence, the interaction term between Volume 2 and AFTER is included in equation (10). Dummy variables in (10-1) include intraday, weekday and year dummies. Based on the explanation in the hypothesis section, the signs of estimated coefficients on Volume $1_{i t}$, Volume $2_{i t}$ and Volume $4_{i t}$ are expected to be negative, negative, and positive, respectively: $b_{11}<0, b_{12}<0$ and $b_{14}>0$ in (10-1). On the contrary, if the CTI4 traders are pure noisy liquidity traders, then the coefficient of Volume $4_{t}$ is expected to be negative. Lastly, we use the following 2SLS models (11) and (12) to test the second hypothesis [H2]. ${ }^{10}$

$$
\begin{aligned}
& B S_{i t}=b_{0}+b_{1} B U Y 1_{i t}+b_{2} S E L L 1_{i t}+b_{3} B U Y 2_{i t}+b_{4} S E L L 2_{i t}+b_{5} B U Y 2_{i t} \times A F T E R \\
& +b_{6} S E L L 2_{i t} \times A F T E R+b_{7} B U Y 4_{i t}+b_{8} \text { SELL }_{i t}+b_{9} \text { Volatility }_{i t} \\
& +b_{10} \text { TTM }_{t}+b_{11} \text { TTM } M_{t}^{2}+\text { Dummy Variables }+e_{t} \\
& A S_{i t}=b_{0}+b_{1} B U Y 1_{i t}+b_{2} S E L L 1_{i t}+b_{3} B U Y 2_{i t}+b_{4} S E L L 2_{i t}+b_{5} B U Y 2_{i t} \times A F T E R \\
& +b_{6} \text { SELL }_{i t} \times \text { AFTER }+b_{7} B U Y 4_{i t}+b_{8} \text { SELL }_{i t}+b_{9} \text { Volatility }_{i t} \\
& +b_{10} T_{T} M_{t}+b_{11} T T M_{t}^{2}+\text { Dummy Variables }+e_{t}
\end{aligned}
$$


where $B S_{i t}$ and $A S_{i t}$ are the bid-spread and ask-spread as defined in (3) and (4). BUYk $k_{i t}$ and $S E L L k_{i t}$ are the square root of the buy and sell number of futures contracts of CTI k. We suppress the square root operator for notational simplicity. When there are more buy orders, the overall bid price goes up and, to stay competitive, the market makers' bid prices will also go up. As a result, the market makers' BS (VWAP - Buy price) shrinks. On the other hand, when there are more sell orders, the market makers have to lower their buy prices to manage the inventory risk, and hence the BS widens. Therefore, the signs of $B U Y k_{i t}$ and $S E L L k_{i t}$ on the $B S_{i t}$ are expected to be negative and positive, respectively, i.e., $b_{1}, b_{3}, b_{7}<0$ and $b_{2}, b_{4}, b_{8}>0$ in (11). Using the same analogy, the signs of $B U Y k_{i t}$ and $S E L L k_{i t}$ on the $A S_{i t}$ are expected to be positive and negative, respectively, i.e., $b_{1}, b_{3}, b_{7}>0$ and $b_{2}, b_{4}, b_{8}<0$ in (12).

How then, do the coefficients of $B U Y k_{i t}$ and $S E L L k_{i t}$ differ by type of trader? Both the BS and AS account for the market maker's effective BAS since the market makers require spreads on the bid and ask sides, respectively. Hence, the combined effect of individual changes in buy (BUYk) and sell (SELLk) trading volumes should similarly affect the half bid-spread (BS) and half ask-spread (AS). For example, in model (10) we expect Volume1 to be negatively associated with the BAS. Thus, the combined effect (sum of coefficients) of BUY1 and SELL1 on the BS in (11) is also expected to be negative. Specifically, in order for the combined effect of BUY1 and SELL1 on BS to be negative, the absolute value of $b_{1}$ must be greater than the absolute value of $b_{2}:\left|b_{1}\right|>\left|b_{2}\right|$ where $b_{1}<0$ and $b_{2}>0$ in (11). Similarly, we expect that the absolute value of the SELL1 coefficient to be greater than BUY1 coefficient in (12): ||$b_{1}|<| b_{2} \mid$ where $b_{1}>0$ and $b_{2}<0$. By the same analogy, we expect similar signs in the regression estimated for institutional traders (CTI2) since we expect their trading volume (Volume2) to be negatively associated with the BAS.

Meanwhile, we anticipate that the trading volume of the off-exchange traders (Volume4) will be positively associated with the BAS. Therefore, we expect an opposite dynamic between coefficients on BUY4 and SELL4 in models (11) and (12). Specifically, it is expected that $\left|b_{7}\right|<\left|b_{8}\right|$ where $b_{7}<0$ and $b_{8}>0$ in (11) and $\left|b_{7}\right|>\left|b_{8}\right|$ where $b_{7}>0$ and $b_{8}<0$ in (12). The in-depth theoretical discussion of the regression coefficients is provided in the results section.

\section{RESULTS}

\section{Univariate Results of Bid-As Spread, Liquidity Supply and Liquidity Demand}

Table 2 shows the yearly estimates of volume, volatility and measures of bid-ask spreads. The main purpose of this table is to identify which types of traders supply and demand liquidity, respectively. With the identifications from this table, we will show how the market makers behave in liquidity provision when trading with liquidity demanders. Results show that the values of the bid-ask spreads (Sell price - Buy price) of market makers (CTI1) and exchange member institutions (CTI2), i.e., BAS and BAS2, respectively, are positive, whereas those of off-exchange traders (CTI4) are consistently negative. The results reveal that the market makers (CTI1) and institutional investors (CTI2) supply liquidity and the offexchange traders (CTI4) demand liquidity. Table 2 also demonstrates that the values of market maker's BAS shrink as volume increases and volatility diminishes. For example, in Panel c, BAS shrinks from 4.91 to 2.11 as volume rises from 160.93 to 204.47 and volatility decreases from 6.30 to 4.24 in the 10 -Year Tnote futures. A greater volume represents smaller order processing cost and more competition in liquidity provision, resulting in a narrower BAS. In addition, Table 2 shows the disaggregation of BAS into the bid spread (BS) and the ask spread (AS) i.e., the market makers' effective BAS = half bid-spread (BS) + half ask-spread (AS) as described in the methodology section. Results show that the difference between BS and AS and the standard deviations of BS and AS are greater (less) when volatility is high (low) in general. This finding indicates that market maker's buy and sell prices more actively change in response to high volatility. We provide more rigorous multivariate analyses on the BS and AS in Table 5 and 6. 


\section{Relation Between Market Maker's Effective Bid-Ask Spread and Volatility}

Table 3 shows the results of the mean values of BAS, Volatility (VWVolat), HiLoVolat and NPrice for each decile as described in Figure 2. The purpose of this table is to show that the market maker's effective BAS may be negative rather than positive when volatility is high and accordingly that their BASs and volatility become inversely associated in this case. This recognition is critical in an empirical study since a priori relation between BAS and volatility is positive in market microstructure models for the market makers to protect their positions when volatility increases. However, market makers' effective BAS can be negative when volatility rises and the price drops (rises) before they can sell (buy).

Our results in Table 3 demonstrate that the market makers in the T-note futures market may generate losses when the price volatility is high. The negative sign of the effective BAS in deciles 1 to 3 indicates losses in market making. The highest losses appear to coincide with periods of high volatility. For instance, in Table 3 Panel a, the first decile has an average BAS of -8.34 at the time when volatility is high $($ Volatility $=2.92$, HiLoVolat $=3.33$, NPrice $=6.87)$. At the same time, the highest average BAS of 11.62 in decile 10 also coincides with the period of high volatility (Volatility $=2.99$, HiLoVolat $=3.61$ and NPrice=7.17).

Moreover, the results confirm that the overall average BAS for each of T-note futures contracts is positive i.e., 1.24, 1.74 and 2.84 for the 2-Year, 5-Year and 10-Year futures contracts, respectively. Accordingly, the market makers generate profit by successfully widening the BAS when the volatility rises for most of the time.

TABLE 2

UNIVARIATE RESULTS OF INTRADAY VOLUME, VOLATILITY AND BID-ASK SPREADS

\begin{tabular}{|c|c|c|c|c|c|c|c|c|c|}
\hline & Volume & Volatility & $\begin{array}{l}\text { BAS } \\
\text { (CTI1) }\end{array}$ & $\begin{array}{l}\text { BAS2 } \\
\text { (CTI2) }\end{array}$ & $\begin{array}{l}\text { BAS4 } \\
\text { (CTI4) }\end{array}$ & $\mathrm{BS}$ & $\mathrm{AS}$ & $\begin{array}{l}\text { Stdev } \\
\text { BS }\end{array}$ & $\begin{array}{l}\text { Stdev } \\
\text { AS }\end{array}$ \\
\hline \multicolumn{10}{|c|}{ Panel a: 2-Year T-note futures } \\
\hline 2003 & 18.16 & $2.73 *$ & $2.49 *$ & $2.95 *$ & $-0.46 *$ & $1.43 *$ & $0.76 *$ & 8.96 & 8.36 \\
\hline 2004 & 30.72 & $2.47 *$ & $1.22 *$ & 2.13* & $-0.26 *$ & $0.55 *$ & $0.64 *$ & 5.54 & 4.34 \\
\hline 2005 & 53.55 & $2.26 *$ & $1.39 *$ & $0.78 *$ & $-0.94 *$ & $0.74 *$ & $0.65 *$ & 2.82 & 2.80 \\
\hline 2006 & 71.90 & $2.06 *$ & $0.85 *$ & $0.89 *$ & $-1.31 *$ & $0.43 *$ & $0.41 *$ & 2.26 & 2.20 \\
\hline \multicolumn{10}{|c|}{ Panel b: 5-Year T-note futures } \\
\hline 2003 & 107.66 & $5.08 *$ & $1.97 *$ & $2.25 *$ & $-2.07 *$ & $0.90 *$ & $1.07 *$ & 7.60 & 6.18 \\
\hline 2004 & 124.41 & $4.26 *$ & $1.78 *$ & $1.35 *$ & $-1.56 *$ & $0.87 *$ & $0.91 *$ & 4.66 & 4.11 \\
\hline 2005 & 139.61 & 3.81* & $1.59 *$ & $0.62 *$ & $-1.93 *$ & $0.77 *$ & $0.83 *$ & 4.22 & 4.17 \\
\hline 2006 & 142.38 & 3.36* & $1.67 *$ & $0.68 *$ & $-2.07 *$ & $0.91 *$ & $0.76^{*}$ & 3.30 & 3.06 \\
\hline \multicolumn{10}{|c|}{ Panel c: 10-Year T-note futures } \\
\hline 2003 & 160.93 & $6.30 \%$ & 4.91* & $-0.15 *$ & $-1.78 *$ & 2.11* & $2.80 *$ & 7.71 & 7.92 \\
\hline 2004 & 179.53 & $5.25 *$ & $3.06^{*}$ & $0.27^{*}$ & $-1.57^{*}$ & $1.39 *$ & $1.67 *$ & 6.09 & 5.15 \\
\hline 2005 & 186.46 & $4.82 *$ & $2.77 *$ & $0.70 *$ & $-3.02 *$ & $1.28 *$ & $1.49 *$ & 5.26 & 5.44 \\
\hline 2006 & 204.47 & $4.24 *$ & $2.11 \%$ & $0.97 *$ & $-2.94 *$ & $1.12 *$ & $0.99 *$ & 4.35 & 4.31 \\
\hline
\end{tabular}

Table 2 provides the yearly averages of intraday volume, volatility and measures of bid-ask spreads. The last two columns show the standard deviations of market makers' half bid- and half ask-spreads. The purpose of this table is to identify liquidity providers and demanders. The statistically positive bid-ask spread (BAS) represents liquidity supply and the negative BAS stands for liquidity demand. This table also shows preliminary dynamic of the relationship between volume, volatility and the market makers' BAS. 
BAS is the CTI1 market makers' intraday bid-ask spread as defined in (5) i.e., the difference between volume-weighted sell and buy prices. BAS2 and BAS4 are similarly defined as the market makers' BAS but for CTI2 and CTI4 traders. Hence, the positive (negative) value of BAS for CTI k represents that the CTI k trader's volume-weighted sell prices are higher (lower) than buy prices. Liquidity providers have positive BASs. Liquidity demanders have negative BAS since they buy (sell) at the sell (buy) prices of liquidity providers. BS and AS are the market makers' bid spread and ask spread, respectively, as defined in (3) and (4). The sum of BS and AS equals the value of the market maker's BAS. Unlike the total number of contracts, Volume is determined by the definition in (7). The Stdev BS and Stdev AS represent the standard deviations of BS and AS, respectively. Volatility is the volume-weighted volatility (VWVolat) as defined in (8) i.e., the standard deviation of volume-weight trade prices from the VWAP for each intraday interval. The bold-faced estimates with an asterisk are statistically significantly different from zero at the level of $1 \%$.

TABLE 3

MARKET MAKER'S EFFECTIVE BID-ASK SPREAD AND VOLATILITY

\begin{tabular}{|c|c|c|c|c|c|}
\hline BAS Decile & $\mathrm{N}$ & BAS & Volatility & HiLoVolat & NPrice \\
\hline \multicolumn{6}{|c|}{ Panel a: 2-Year T-note futures } \\
\hline 1 & 757 & -8.34 & 2.92 & 3.33 & 6.87 \\
\hline 2 & 757 & -2.62 & 2.49 & 2.49 & 6.09 \\
\hline 3 & 758 & -0.93 & 2.25 & 2.22 & 5.66 \\
\hline 4 & 757 & -0.06 & 1.43 & 1.34 & 4.21 \\
\hline 5 & 757 & 0.36 & 1.85 & 1.78 & 5.08 \\
\hline 6 & 758 & 1.21 & 2.12 & 1.99 & 5.44 \\
\hline 7 & 757 & 2.23 & 2.28 & 2.12 & 5.59 \\
\hline 8 & 758 & 3.49 & 2.32 & 2.06 & 5.51 \\
\hline 9 & 757 & 5.45 & 2.45 & 2.25 & 5.75 \\
\hline 10 & 757 & 11.62 & 2.99 & 3.61 & 7.17 \\
\hline Average & & 1.24 & & & \\
\hline \multicolumn{6}{|c|}{ Panel b: 5-Year T-note futures } \\
\hline 1 & 798 & -7.58 & 4.49 & 8.70 & 9.85 \\
\hline 2 & 799 & -2.64 & 3.95 & 6.85 & 8.60 \\
\hline 3 & 799 & -1.09 & 3.71 & 6.24 & 8.18 \\
\hline 4 & 799 & 0.02 & 3.41 & 5.94 & 7.89 \\
\hline 5 & 799 & 0.89 & 3.50 & 5.93 & 7.95 \\
\hline 6 & 799 & 1.81 & 3.59 & 5.96 & 7.94 \\
\hline 7 & 799 & 2.86 & 3.84 & 6.81 & 8.70 \\
\hline 8 & 799 & 4.24 & 3.85 & 6.62 & 8.42 \\
\hline 9 & 799 & 6.21 & 4.17 & 7.63 & 9.13 \\
\hline 10 & 798 & 12.36 & 4.75 & 9.75 & 10.56 \\
\hline Average & & 1.74 & & & \\
\hline \multicolumn{6}{|c|}{ Panel c: 10 -Year T-note futures } \\
\hline 1 & 799 & -7.62 & 5.48 & 12.97 & 14.03 \\
\hline 2 & 799 & -1.99 & 4.72 & 9.67 & 11.49 \\
\hline 3 & 799 & -0.27 & 4.50 & 9.40 & 11.40 \\
\hline 4 & 800 & 0.98 & 4.46 & 8.99 & 11.08 \\
\hline 5 & 799 & 2.04 & 4.49 & 9.18 & 11.28 \\
\hline 6 & 799 & 3.07 & 4.60 & 9.62 & 11.66 \\
\hline 7 & 800 & 4.25 & 4.70 & 9.75 & 11.80 \\
\hline
\end{tabular}




\begin{tabular}{|c|c|c|c|c|c|}
\hline 8 & 799 & 5.68 & 4.90 & 10.22 & 12.35 \\
\hline 9 & 799 & 7.75 & 5.21 & 11.37 & 13.15 \\
\hline 10 & 799 & 14.54 & 6.01 & 14.40 & 15.34 \\
\hline Average & & 2.84 & & & \\
\hline
\end{tabular}

The purpose of this table is to examine the relation between market maker's effective BASs and volatility. It is expected that market makers may experience losses by realizing negative BASs when volatility is high. Volatility is the volume-weighted volatility (VWVolat) as defined in (8). HiLoVolat represents the high-low volatility i.e., (High-Low)/((High+Low)/2) multiplied by $10^{4}$ for each 30 -minute intraday interval. NPrice is the number of prices where transactions have occurred for each intraday interval. The intraday BASs are grouped in ten deciles with equal number of observations from negative to positive values in an ascending order. The overall average of the intraday BASs across the ten deciles is shown in the row of Average. The shaded numbers represent the lowest values in deciles.

\section{Effects of Trader Type on Market Maker's Effective Bid-Ask Spread}

As we document in Table 3, due to high volatility market makers sometimes experience losses by setting their sell prices lower than prices they paid for the inventory. We examine for $\mathrm{H} 1$ and $\mathrm{H} 2$ how market makers adjust their BASs in response to change in trading volume by traders of different type. Since market makers intend to generate profit from market making, to test $\mathrm{H} 1$ and $\mathrm{H} 2$, we keep only observations with the positive BAS in our sample. We repeat same tests using full dataset for a robustness check; the results do not change materially.

The 2SLS estimation results of the equations $(9-1,9-2,9-3)$ for 2-Year, 5-Year, and 10-Year T-note futures are reported in Table 4 Panel a, b, and c respectively. The purpose of this analysis is to determine the coefficient of overall volume (Volume) in (9-1) and decompose its coefficient by type of trader with $(10-1)$.

We find that across T-note futures of all maturities the aggregate trading volume (Volume) exhibits negative coefficients on the market maker's BAS in (9-1): $-0.40,-0.60$, and -0.43 for 2-Year, 5 -Year and 10 -Year T-note futures respectively. The negative coefficient implies that the effects of economies of scale (reduction in order processing cost) and competition in market making on the BAS are dominant when the overall trading volume increases. This result confirms the finding of the negative association between BAS and Volume in Table 2. In addition, the coefficient on Volatility in model (9-1) is significantly positive for all maturities: $25.47,35.54$, and 29.76 for 2-Year, 5-Year and 10-Year T-note futures respectively. This finding indicates that the market makers widen their BASs when price uncertainty rises to protect against risk. ${ }^{11}$ The F-statistic in Table 5 is for joint endogeneity test of volatility and volume in the BAS regression equation in (9-1). The null hypothesis is that volatility and volume are not endogenous. Results reject the null hypothesis and show that 2SLS estimation is consistent and preferred over OLS. ${ }^{12}$

The test results of the first hypothesis [H1] using the 2SLS regression equations in (10-1) - (10-5) are similarly organized and reported in the right half of Table 4 Panel a, b, and c. The regression coefficients on Volume1 and Volume2 that represent trading volume of the market makers (CTI1) and institutional traders (CTI2), respectively, are negative whereas those of the individual traders (CTI4) are positive for Tnote futures of all maturities. The sum of coefficients on the volumes disaggregated by trader type is negative for all futures maturities: for example, for 5-Year T-note futures (Table 5 Panel b) the sum of coefficients on the volume variables is $(-0.72)+(-0.50)+0.14+0.38=-0.70<0$. The decomposition of the volume by trader type demonstrates that the negative coefficient on Volume observed in model (9-1) is mainly driven by the trading volume of market makers (Volume1) and institutional traders (Volume2). In other words, when market makers observe an increased trading volume of market makers and institutional traders the economies of scale and the competition in market making cause market makers to narrow their BAS. On the other hand, when off-exchange traders (CTI4) increase their trading volume (Volume4) market makers widen their BAS, which is confirmed by the statistically significant positive coefficient on 
Volume 4 of 0.38 . We observe the qualitatively same results for the 2-Year and 10-Year T-notes in Panels $\mathrm{a}$ and $\mathrm{c}$ as well. Therefore, the results in Table 4 support the first hypothesis. ${ }^{13}$

Table 4 also provides important results concerning whose trading volume increases volatility. In model (10-2) the coefficients of Volume1 and Volume 2 are consistently negative whereas that on Volume4 is consistently positive: for instance, for 5-Year T-Note futures (Table 4 Panel b) coefficients on Volume1 and Volume 2 are -0.03 and -0.11 and the coefficient on Volume 4 is 0.07 . This indicates that trading volume of market makers (CTI1) and institutions (CTI2) tend to reduce volatility whereas trading volume of offexchange traders (CTI4) tend to increase volatility.

The results in Table 4 allow us to make important conclusions about off-exchange traders (CTI4). First, the statistically significant positive coefficient on Volume4 in model (10-1) allows us to conclude that CTI4 traders consume liquidity and create risk for the market makers. Furthermore, as off-exchange traders tend to increase volatility the market makers widen their BASs accordingly.

TABLE 4

EFFECTS OF TRADER TYPE ON MARKET MAKER'S EFFECTIVE BID-ASK SPREAD

Panel a: 2-Year T-note futures

\begin{tabular}{|c|c|c|c|c|c|c|c|c|}
\hline Model & $(9-1)$ & $(9-2)$ & $(9-3)$ & $(10-1)$ & $(10-2)$ & $(10-3)$ & $(10-4)$ & $(10-5)$ \\
\hline $\begin{array}{l}\text { Dependent } \\
\text { Variable }\end{array}$ & BAS & Volatility & Volume & BAS & Volatility & Volume1 & Volume2 & Volume4 \\
\hline Volume & $-0.40 *$ & $-0.07 *$ & & & & & & \\
\hline Volume1 & & & & $-0.79 *$ & $-0.12 *$ & & $-4.95 *$ & $-0.10 *$ \\
\hline Volume2 & & & & $-0.41 *$ & $-0.10 *$ & $-4.72 *$ & & $-0.98 *$ \\
\hline $\begin{array}{r}\text { Volume } 2 \mathrm{x} \\
\text { AFTER } \\
\end{array}$ & & & & $0.26 *$ & & & & \\
\hline Volume4 & & & & $0.22 *$ & $0.15 *$ & $1.63 *$ & $2.28 *$ & \\
\hline Volatility & 25.47* & & 261.90* & 28.93* & & $163.67 *$ & 157.94* & 174.36* \\
\hline TTM & $-0.11 *$ & & & $-0.28^{*}$ & & & & \\
\hline $\mathrm{TTM}^{2}$ & $<0.00$ & & & $<0.00^{*}$ & & & & \\
\hline Lag Volatility & & $3.42 *$ & & & 3.01* & & & \\
\hline Lag Volume & & & $2.55^{*}$ & & & & & \\
\hline Lag Volume1 & & & & & & $3.49 * *$ & & \\
\hline Lag Volume2 & & & & & & & 2.82* & \\
\hline Lag Volume4 & & & & & & & & 3.13* \\
\hline $\begin{array}{l}\text { Intraday } \\
\text { dummies }\end{array}$ & Yes & Yes & & Yes & Yes & & & \\
\hline $\begin{array}{l}\text { Weekday } \\
\text { dummies }\end{array}$ & Yes & & & Yes & & & & \\
\hline Year dummies & Yes & & Yes & Yes & & Yes & Yes & Yes \\
\hline Intercept & 3.61* & $1.60 *$ & $-58.03 *$ & 2.83* & 1.41* & $-40.59 *$ & $-40.52 *$ & $-36.45 *$ \\
\hline R-square & $0.20 *$ & $0.19 *$ & $0.51 *$ & $0.37 *$ & $0.21 *$ & $0.35 *$ & $0.59 *$ & $0.35 *$ \\
\hline $\mathrm{N}$ & 5,013 & 5,013 & 5,013 & 5,013 & 5,013 & 5,013 & 5,013 & 5,013 \\
\hline F-statistic & 11.68* & & & & & & & \\
\hline
\end{tabular}


Panel b: 5-Year T-note futures

\begin{tabular}{|c|c|c|c|c|c|c|c|c|}
\hline Model & $(9-1)$ & $(9-2)$ & $(9-3)$ & $(10-1)$ & $(10-2)$ & $(10-3)$ & $(10-4)$ & $(10-5)$ \\
\hline $\begin{array}{l}\text { Dependent } \\
\text { Variable }\end{array}$ & BAS & Volatility & Volume & BAS & Volatility & Volume1 & Volume2 & Volume4 \\
\hline Volume & $-0.60 *$ & $-0.11 *$ & & & & & & \\
\hline Volume1 & & & & $-0.72 *$ & $-0.03 *$ & & $-8.29 *$ & $-7.34 *$ \\
\hline Volume2 & & & & $-0.50 *$ & $-0.11 *$ & $-2.52 *$ & & $-3.28 *$ \\
\hline $\begin{array}{r}\text { Volume } 2 \mathrm{x} \\
\text { AFTER } \\
\end{array}$ & & & & $0.14 *$ & & & & \\
\hline Volume4 & & & & $0.38 *$ & $0.07 *$ & $1.78 *$ & $2.64 *$ & \\
\hline Volatility & 35.54* & & 550.82* & $27.32 *$ & & 311.45* & 514.10* & 596.81* \\
\hline TTM & $-1.04 *$ & & & $-1.35 *$ & & & & \\
\hline $\mathrm{TTM}^{2}$ & $0.01 *$ & & & 0.01* & & & & \\
\hline Lag Volatility & & $5.69 *$ & & & $4.65 *$ & & & \\
\hline Lag Volume & & & $2.05 *$ & & & & & \\
\hline Lag Volume1 & & & & & & $2.59 *$ & & \\
\hline Lag Volume2 & & & & & & & $3.23 *$ & \\
\hline Lag Volume4 & & & & & & & & $4.47 *$ \\
\hline $\begin{array}{l}\text { Intraday } \\
\text { dummies }\end{array}$ & Yes & Yes & & Yes & Yes & & & \\
\hline $\begin{array}{l}\text { Weekday } \\
\text { dummies }\end{array}$ & Yes & & & Yes & & & & \\
\hline Year dummies & Yes & & Yes & Yes & & Yes & Yes & Yes \\
\hline Intercept & $-1.31 *$ & 2.76* & $-194.09 *$ & $1.47^{*}$ & $2.47 *$ & $-115.57^{*}$ & $-193.46^{*}$ & $-206.64 *$ \\
\hline R-square & $0.09 *$ & $0.22 *$ & $0.39 *$ & $0.26^{*}$ & $0.27 *$ & $0.32 *$ & $0.31 *$ & $0.14 *$ \\
\hline $\mathrm{N}$ & 5,249 & 5,249 & 5,249 & 5,249 & 5,249 & 5,249 & 5,249 & 5,249 \\
\hline F-statistic & 10.14* & & & & & & & \\
\hline
\end{tabular}

Panel c: $10-$ Year T-note futures

\begin{tabular}{|l|c|c|c|c|c|c|c|c|}
\hline Model & $\mathbf{( 9 - 1 )}$ & $(9-2)$ & $(9-3)$ & $(10-1)$ & $(10-2)$ & $(10-3)$ & $(10-4)$ & $(10-5)$ \\
\hline $\begin{array}{l}\text { Dependent } \\
\text { Variable }\end{array}$ & BAS & Volatility & Volume & BAS & Volatility & Volume1 & Volume2 & Volume4 \\
\hline Volume & $\mathbf{- 0 . 4 3 *}$ & $\mathbf{- 0 . 0 8 *}$ & & & & & & \\
\hline Volume1 & & & & $-\mathbf{0 . 5 3 *}$ & $\mathbf{- 0 . 0 8 *}$ & & $0.77^{*}$ & $\mathbf{2 . 5 2 *}$ \\
\hline Volume2 & & & & $\mathbf{- 0 . 4 0 *}$ & $\mathbf{- 0 . 1 0 *}$ & $\mathbf{- 1 8 . 8 0 *}$ & & $\mathbf{- 1 1 . 3 2 *}$ \\
\hline $\begin{array}{l}\text { Volume2 } \\
\text { AFTER }\end{array}$ & & & & $\mathbf{0 . 2 1 *}$ & & & & \\
\hline Volume4 & & & & $\mathbf{0 . 1 4 *}$ & $\mathbf{0 . 1 2 *}$ & $-3.60^{*}$ & $-0.53^{*}$ & \\
\hline Volatility & $\mathbf{2 9 . 7 6 ^ { * }}$ & & $\mathbf{7 3 4 . 8 2 *}$ & $\mathbf{2 4 . 0 3 *}$ & & $\mathbf{1 4 3 2 . 3 *}$ & $\mathbf{4 5 6 . 9 2 *}$ & $\mathbf{8 4 4 . 9 6 *}$ \\
\hline TTM & $\mathbf{- 1 . 5 6 *}$ & & & $-\mathbf{1 . 7 1}^{*}$ & & & & \\
\hline $\mathrm{TTM}^{2}$ & $\mathbf{0 . 0 1 *}$ & & & $\mathbf{0 . 0 1 *}$ & & & & \\
\hline
\end{tabular}




\begin{tabular}{|l|l|l|l|l|l|l|l|l|}
\hline $\begin{array}{l}\text { Lag } \\
\text { Volatility }\end{array}$ & & $\mathbf{4 . 9 5 *}$ & & & $\mathbf{4 . 0 5 *}$ & & & \\
\hline Lag Volume & & & $\mathbf{1 . 7 6 *}$ & & & & & \\
\hline Lag Volume1 & & & & & & $\mathbf{6 . 8 8}^{*}$ & & \\
\hline Lag Volume2 & & & & & & & $\mathbf{1 . 8 3} *$ & \\
\hline Lag Volume4 & & & & & & & & $\mathbf{3 . 2 1 *}$ \\
\hline $\begin{array}{l}\text { Intraday } \\
\text { dummies }\end{array}$ & Yes & Yes & & Yes & Yes & & & \\
\hline $\begin{array}{l}\text { Weekday } \\
\text { dummies }\end{array}$ & Yes & & & Yes & & & & \\
\hline $\begin{array}{l}\text { Year } \\
\text { dummies }\end{array}$ & Yes & & Yes & Yes & & Yes & Yes & Yes \\
\hline Intercept & $\mathbf{1 . 2 7 *}$ & $\mathbf{3 . 5 5 *}$ & $\mathbf{- 3 2 5 . 4 *}$ & $\mathbf{4 . 4 9 *}$ & $\mathbf{3 . 1 6 *}$ & $\mathbf{- 6 5 9 . 5 8 *}$ & $\mathbf{- 2 1 0 . 5 1 *}$ & $\mathbf{- 3 7 3 . 7 8 *}$ \\
\hline R-square & $0.09 *$ & $0.20^{*}$ & $0.32 *$ & $0.20 *$ & $0.25^{*}$ & $0.04 *$ & $0.40^{*}$ & $0.11^{*}$ \\
\hline N & 5,839 & 5,839 & 5,839 & 5,839 & 5,839 & 5,839 & 5,839 & 5,839 \\
\hline F-statistic & $\mathbf{4 . 0 5 *}$ & & & & & & & \\
\hline
\end{tabular}

The results of 2SLS estimation of the models (9-1), (9-2), and (9-3) for the 2-Year, 5-Tear and 10-Year T-note futures are presented in the left half of Panels a, b and c respectively. In the right half of the table, we report results of models (10-1) to (10-5). The dependent variable is the market makers' intraday positive effective bid-ask spreads (BASs). Volume represents the aggregate volume across all trader types as given in (7). Volumek, where $k=1,2$, and 4, respectively, for each CTI1, CTI2 and CTI4, is the disaggregate trading volume as defined in (6). AFTER is a dummy that takes one if the observation belongs to the period from 2005 and 2006 and zero, otherwise. Volatility is the volume-weighted average volatility as defined in (8). TTM is the number of days to maturity. $\mathrm{TTM}^{2}$ is squared value of TTM. Lagged variables (Lag Volatility and Lag Volume $k$ ) the value of the variable from the previous intraday interval. The estimates of coefficients are multiplied by 10 for a better exposition of the results except for Intercept. The bold-faced estimates with an asterisk are statistically significantly different from zero at the level of $1 \%$. The boldfaced numbers and the bold italic numbers are statistically significant at the $5 \%$ and $10 \%$ level, respectively. The F-statistic is for joint endogeneity test of volatility and volume in the BAS regression equation. The null hypothesis is that volatility and volume are exogenous.

\section{Effects of Trader Type on Inner Process of Market Making}

We have previously shown in Table 4 that the trading volume (Volume4) by off-exchange (CTI4) traders convey risk, and hence, the market makers widen their bid-ask spreads. Next, we would like to explore the inner process by which the market makers react to the trading volumes. An important preliminary step is to examine whether the CTI4 traders increase price volatility and the market makers (CTI1) and institutional traders (CTI2) mitigate it.

We have already reported in the model (10-2) of Table 4 that market makers (CTI1) and institutions (CTI2) reduce volatility whereas off-exchange traders (CTI4) increase it. Figure 3 supplies complementary results. In Panels a, b, and c of Figure 3, we analyze whether "buy" or "sell" trades dominate when price changes direction from the previous intraday period. Panel $\mathrm{d}$ exhibits the relation between lagged CTI4 traders' buy and sell shares to current price changes. Results in Panels a, b and c show that the market makers (CTI1) and institutions (CTI2) buy more and sell less when price falls, while the reverse is true when price rises. ${ }^{14}$ Their trading patterns are consistent with the contrarian strategy, which is known to reduce price volatility. Meanwhile, the off-exchange traders (CTI4) sell more and buy less when price falls while the reverse pattern of trades occur when price rises. Hence, the trading pattern of the off-exchange traders are consistent with the momentum strategy, which exacerbates volatility. 
Given the trading patterns by trader type as shown in Figure 3, we expect that the market makers are aware of the patterns and take them into account especially when they face risk. Market makers' actions to protect themselves against risk are stated in the second hypothesis [H2]. That is, market maker's half effective bid-spread (VWAP - Buy price) widens as market makers (CTI1) decrease buy prices when they trade with the off-exchange traders (CTI4). Similarly, market maker's half effective ask-spread (Sell price - VWAP) widens as market makers (CTI1) increase sell prices when they trade with the off-exchange traders (CTI4).

We test the H2 using the 2SLS regression equations (11) and (12). Test results are summarized in Table 5 and grouped by the T-note maturity. The estimation results of the model (10-1) from Table 4 are included in Table 5 to demonstrate the effect of decomposition of the coefficients. As described in the methodology section, in model (11) the signs of coefficients on BUYk and SELL $k$ (where $k=1,2,4)$ are negative and positive respectively, which is consistent with our expectations. For example, for 5-Year T-notes futures in model (11) coefficients on BUY1 and SELL1 (which represent buy and sell orders of the marker makers) are -1.32 and 1.03 respectively; coefficients on BUY2 and SELL2 (which represent buy and sell orders of the exchange member institutions) are -0.74 and 0.45 respectively; coefficients on BUY4 and SELL4 (which represent buy and sell orders of the off-exchange traders) are -0.31 and 0.67 respectively. The negative coefficient on BUY1, BUY2, BUY4 variables in model (11) indicates that the market makers increase buy price, and hence the market makers' half bid-spread (BS =VWAP - Buy price) shrinks when there are more buy orders. On the other hand, the positive coefficient on the SELL1, SELL2, and SELL4 variables in (11) indicate that the market makers decrease buy price to avoid risk, so the BS widens when more sell orders come to the market. In the second hypothesis [H2], we test whether the market makers exhibit defensive behavior when trading with the off-exchange (CTI4) traders. The results clearly confirm our expectations. That is, in the model (11) in Table 5 the absolute value of coefficients of BUY4 is less than the absolute value of the coefficients on SELL4. Specifically, $|-0.39|<|0.57|,|-0.36|<|0.67|$ and $|-0.19|$ $<|0.37|$ for 2-Year, 5-Year and 10-Year T-notes futures, respectively. These results indicate that the market makers are more sensitive to the CTI4's sell trades than buy trades when they set buy prices. More importantly, the results reveal that the market makers are concerned more about adverse selection risk when buying from the CTI4 traders than about being competitive.

In model (12) in Table 5 we estimate the effect of trading volume of different traders on market makers half ask spread. The estimated coefficients on BUY $k$ and SELL $k$ (where $k=1,2,4$ ) variables are positive and negative respectively, which is in line with our expectations. For example, for 5-Year T-notes futures coefficients in model (12) on BUY1 and SELL1 (which represent buy and sell orders of the marker makers) are 0.69 and -0.92 respectively; coefficients on BUY2 and SELL2 (which represent buy and sell orders of the exchange member institutions) are 0.45 and -0.57 respectively; coefficients on BUY4 and SELL4 (which represent buy and sell orders of the off-exchange traders) are 0.43 and -0.23 respectively. The positive coefficients on BUY1, BUY2, BUY4 variables in model (12) indicate that the market makers increase ask price to avoid risk, and, hence, the market makers' half ask-spread (AS =Ask price - VWAP) widens when there are more buy orders. On the other hand, the negative coefficient on the SELL1, SELL2, and SELL4 variables in model (12) indicate that the market makers decrease ask price to stay competitive, so the AS narrows when more sell orders come to the market. In the second hypothesis, we test whether the market makers exhibit defensive behavior when trading with CTI4 traders. The findings also confirm our expectations. That is, in the model (12) in Table 5 the absolute value of coefficients of BUY4 is greater than the absolute value of the coefficients on SELL4. Specifically, for 5-Year T-note futures $|0.43|>|-0.23|$. These results indicate that the market makers are more sensitive to the CTI4's buy trades than sell trades when they set sell prices. More importantly, the results reveal that the market makers are more concerned about adverse selection risk when selling to the CTI4 traders than about being competitive. Essentially similar results are demonstrated by 2-Year and 10-Year T-note futures, although the results are statistically insignificant. Combined results of estimation of models (11) and (12) exhibit that the market makers are more concerned about adverse selection risk when they buy from the CTI4 traders than on the effects of competitive sell volumes by the CTI 4 traders. ${ }^{15}$ 
The results in Table 5 effectively show the decomposition of the coefficients of trading volume. For instance, the coefficient of Volume4 in model (10-1), which is 0.38 , is positive since the sum of the coefficients of BUY4 and SELL4 $(-0.31+0.43+0.67-0.23=0.54)$ is positive for the 5 -Year T-note futures. The qualitatively similar results appear for the 2-Year and 10-Year T-notes as well. In summary, the results in Table 5 support our second hypothesis. ${ }^{16}$

We test the same hypotheses using full data sample that includes both negative and positive BASs. Results of the robustness analyses are reported in Appendix.

\section{FIGURE 3}

\section{RELATION BETWEEN DIRECTION OF TRADE AND CHANGE OF PRICE}

$<2$-Year T-Notes $>$
$<5$-Year T-Notes $>$

Panel a: Market makers' (CTI1) ratios of buy and sell volume

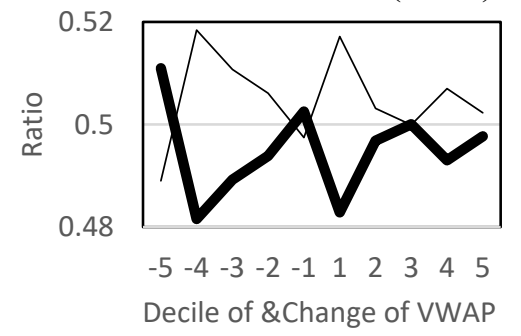

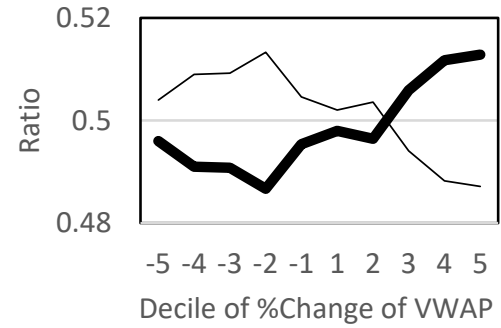

Panel b: Institutions' (CTI2) ratios of buy and sell volume
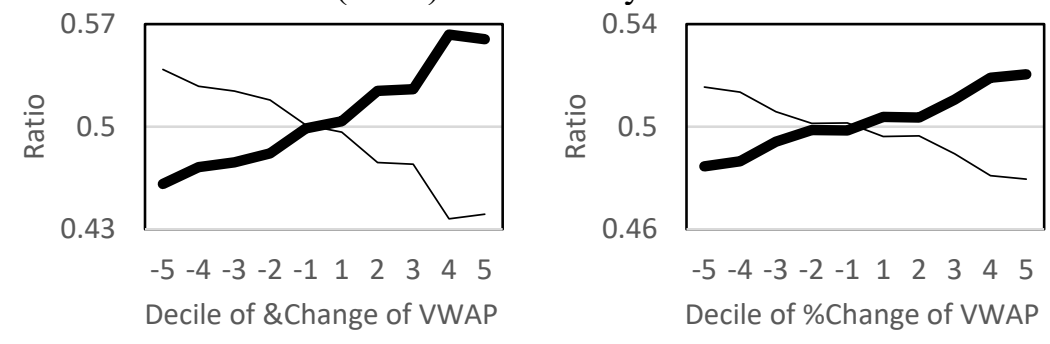

Panel c: Off-exchange traders' (CTI4) ratios of buy and sell volume

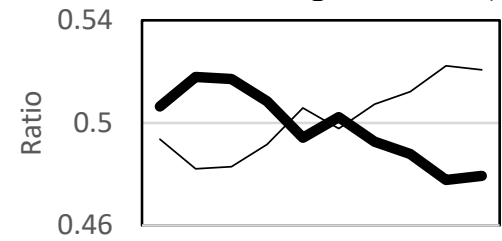

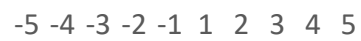

Decile of \&Change of VWAP

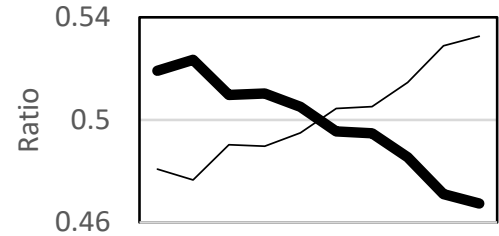

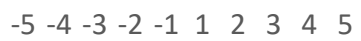
Decile of \%Change of VWAP
$<10$-Year T-Notes $>$

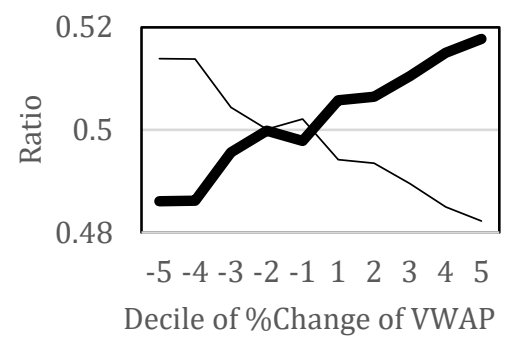

Panel d: Off-exchange traders' (CTI4) ratios of lagged buy and sell volume
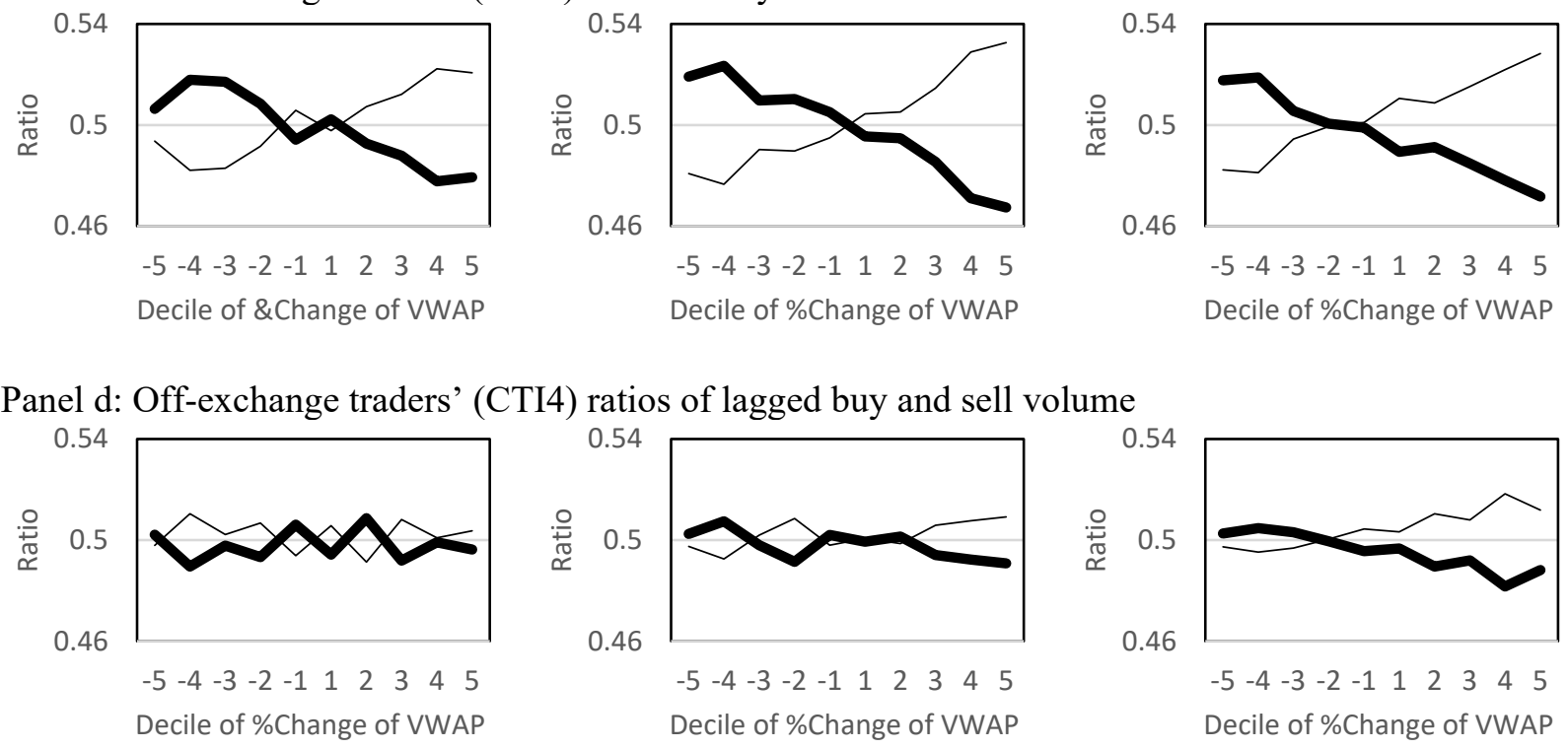

122 Journal of Accounting and Finance Vol. 21(5) 2021 
TABLE 5

EFFECTS OF TRADER TYPE ON INNER PROCESS OF MARKET MAKING

\begin{tabular}{|c|c|c|c|c|c|c|c|c|c|}
\hline \multirow{2}{*}{$\begin{array}{l}\text { Futures contract } \\
\text { Model }\end{array}$} & \multicolumn{3}{|c|}{ 2-Year T-notes } & \multicolumn{3}{|c|}{ 5-Year T-notes } & \multicolumn{3}{|c|}{ 10-Year T-notes } \\
\hline & $(10-1)$ & (11) & (12) & $(10-1)$ & (11) & (12) & $(10-1)$ & (11) & (12) \\
\hline Dependent Variable & BAS & $\mathrm{BS}$ & AS & BAS & $\mathrm{BS}$ & AS & BAS & $\mathrm{BS}$ & AS \\
\hline Volume1 & $-0.79 *$ & & & $-0.72 *$ & & & $-0.53 *$ & & \\
\hline BUY1 & & $-1.20 *$ & $0.72 *$ & & $-1.32 *$ & $0.69 *$ & & $-1.10 *$ & $0.43 *$ \\
\hline SELL1 & & $0.92 *$ & $-0.93 *$ & & $1.03 *$ & $-0.92 *$ & & $0.84 *$ & $-0.70 *$ \\
\hline Volume2 & $-0.41 *$ & & & $-0.50 *$ & & & $-0.40 *$ & & \\
\hline BUY2 & & $-0.01 *$ & $0.16^{*}$ & & $-0.74 \%$ & $0.45 *$ & & $-0.61 *$ & $0.05 *$ \\
\hline SELL2 & & $0.28 *$ & $-0.30 *$ & & $0.45 *$ & $-0.57 *$ & & $0.38 *$ & $-0.15 *$ \\
\hline Volume2 x AFTER & $0.26 *$ & & & $0.14 *$ & & & $0.21 *$ & & \\
\hline BUY2 x AFTER & & $-0.60 *$ & $0.24 *$ & & $-0.08 *$ & $-0.03 *$ & & $0.12 *$ & $0.24^{*}$ \\
\hline SELL2 x AFTER & & $0.37 *$ & $-0.07 *$ & & $0.23 *$ & $0.07 *$ & & $0.01 *$ & $-0.18 *$ \\
\hline Volume4 & $0.22 *$ & & & $0.38 *$ & & & $0.14 *$ & & \\
\hline BUY4 & & $-0.39 *$ & $0.36 *$ & & $-0.31 *$ & $0.43 *$ & & $-0.19 *$ & $0.22 *$ \\
\hline SELL4 & & $0.57 *$ & $-0.14 *$ & & $0.67 *$ & $-0.23 *$ & & $0.37 *$ & $-0.04 *$ \\
\hline Volatility & 28.93* & $11.58 *$ & $8.77 *$ & $27.32 *$ & $10.86^{*}$ & $8.20 *$ & $24.03 *$ & $8.66^{*}$ & 8.06* \\
\hline TTM & $-0.28^{*}$ & $-0.25^{*}$ & $-0.06^{*}$ & $-1.35 *$ & $-1.08 *$ & $-0.83 *$ & $-1.71 \%$ & $-1.36 *$ & $-0.84 \%$ \\
\hline $\mathrm{TTM}^{2}$ & $<0.00^{*}$ & $<0.00$ & $<0.00^{*}$ & $0.01 *$ & $0.01 *$ & $0.01 *$ & $0.01 *$ & $0.01 *$ & 0.01* \\
\hline Intraday dummies & Yes & Yes & Yes & Yes & Yes & Yes & Yes & Yes & Yes \\
\hline Weekday dummies & Yes & Yes & Yes & Yes & Yes & Yes & Yes & Yes & Yes \\
\hline Year dummies & Yes & Yes & Yes & Yes & Yes & Yes & Yes & Yes & Yes \\
\hline Intercept & $2.83 *$ & $2.35 *$ & $2.08 *$ & $1.47 *$ & $1.38 *$ & $2.78 *$ & $4.49 *$ & $3.62 *$ & $3.48 *$ \\
\hline R-square & $0.37 *$ & $0.11 *$ & $0.12 *$ & $0.26^{*}$ & $0.11 *$ & $0.07^{*}$ & $0.20 *$ & $0.06^{*}$ & $0.06^{*}$ \\
\hline $\mathrm{N}$ & 5,013 & 5,013 & 5,013 & 5,249 & 5,249 & 5,249 & 5,839 & 5,839 & 5,839 \\
\hline
\end{tabular}

The model (10-1) is estimated using the 2SLS approach detailed in the methodology section. We also use 2SLS approach to estimate models (11) and (12). The 2SLS model include the equations (11) and (12) with $(10-2,10-3,10-4,10-5)$ as mentioned in endnote 10 . The results in models (10-1) are copied from Table 4. BUY $k$ and SELL $k$ are the square root of the buy and sell number of futures contracts of CTI $k$, where $\mathrm{k}=1,2$, and 4 , for each intraday interval. BS, AS and BAS stand for the market maker's effective bidask spread, half bid-spread and half ask-spread as defined in (3), (4) and (5), respectively. The estimates of coefficients are multiplied by 10 for a better exposition of the results except for Intercept. The bold-faced estimates with an asterisk are statistically significantly different from zero at the level of $1 \%$. The boldfaced numbers and the bold italic numbers are statistically significant at the $5 \%$ and $10 \%$ level, respectively. 


\section{CONCLUSION}

This article examines the relation between the market makers' bid-ask spreads (BASs) and trading volume of different traders using the U.S. T-note futures data. In the data, the intraday trading volume is presented separately for market makers (CTI1), exchange member institutional traders (CTI2), other member traders (CTI3) and off-exchange traders (CTI4). Following Harris (2003, pp. 422-426) methodology, we calculate the effective BAS and, using volume weighted average price, we split it into the bid spread and ask spread. The market makers' bid and ask spreads correspond to the transaction costs of a sale and a purchase for liquidity demanders, respectively. The contributions of this paper are summarized as follows.

Firstly, we find that the values of the bid-ask spreads of CTI1 and CTI2 are positive whereas those of CTI4 are consistently negative, meaning that the market makers and institutional investors supply liquidity whereas the CTI4 traders demand liquidity. Although the market makers' BAS is positive on average, during times of high price volatility it can turn negative and thus cause losses for marker makers.

Our results show that the trading volume aggregated from all trader types exhibits a negative association with the market maker's BAS. Our interpretation is that the effects of economies of scale and competition in market making on the BAS are dominant when the overall trading volume increases. When we disaggregate the trading volume by the type of trader, the trading volumes of market makers (CTI1) and institutional traders (CTI2) is negatively associated with the BAS whereas the trading volume of the offexchange traders (CTI4) is positively associated with the BAS. Hence, the aforementioned negative association between the aggregate volume and BAS is driven by the market makers and institutional traders. Meanwhile, BAS widens when the CTI4 traders increase their trading volume. These findings are consistent with prior literature that demonstrate that CTI4 traders increase volatility that cause market makers to widen the BAS. In fact, our results from the 2SLS regressions show that the trading volume of CTI4 traders is positively associated with volatility. We also find, that the CTI4 traders are not pure noisy liquidity providers. The positive association between CTI4 trading volume and the BAS indicate that CTI4 traders consume liquidity. If CTI4 traders were pure liquidity providers, then their trading volume would have been negatively associated with the BAS.

We split the BAS into the bid spread and the ask spread to investigate the inner process by which the market makers react to the change in trading volume by each type of trader. Essentially, we study why the trading volume of the CTI4 traders is positively associated with BAS. Our article is the first to provide empirical evidence that the market makers widen the bid spreads (VWAP - Market makers' buy price) by decreasing rather than increasing buy prices when the CTI4 traders increase their buy and sell trading volumes. Similarly, the market makers widen the ask spreads (Market makers' sell price - VWAP) by increasing rather than decreasing their sell prices when the CTI4 traders increase their buy and sell trading volumes. In other words, when the CTI4 traders increase their buy and sell trading volume, both the ask and the bid spreads increase, leading to a wider BAS. From the theoretical point of view, these findings reveal that, when setting prices, the market makers are more concerned about protecting themselves from the adverse selection risk when interacting (buying and selling) with the CTI4 traders.

\section{ENDNOTES}

1. Previous literature identified multiple variables that influence market makers' decisions about BAS such as order processing cost (Demsetz, 1968; Tinic, 1972; Huang and Stoll, 1997), competition between market makers (Demsetz, 1968; Schwartz, 1988, McInish and Wood, 1992), inventory holding cost (Stoll, 1978; Amihud and Mendelson, 1980; Huang and Stoll, 1997) and adverse selection risk (Glosten and Milgrom, 1985; Hasbrouck, 1988; Huang and Stoll, 1997; Easley and O'Hara, 1987).

2. Similarly, Chung et al. (1999) find that the BAS at the NYSE are narrow when the bid and ask prices are quoted from the limit-order book which stores the standing bid and ask quotes from both specialists and public limit orders. However, BASs are wide when the bid and ask prices are quoted by only specialists. Wang et al. (1994) use the S\&P 500 Index Futures data around the stock market crisis on October 19, 1987 and they also find that BAS is inversely related to the number of market makers. 
3. In addition, greater trading volume can cause a dealer's inventory position to deviate from the optimal levels. The inventory holding cost increases as the inventory position becomes non-optimal. Market makers widen the BAS to hedge against the increase in the inventory holding costs (Amihud and Mendelson, 1980).

4. Momentum traders increase (decrease) their net buy positions when prices increase (decrease). Therefore, momentum trades pressure prices to change even further in the same direction as shown in the past. In contrast, contrarian traders decrease (increase) net buy positions when prices increase (decrease). Hence, contrarians dampen price changes, since they buy (sell) when prices increase (decrease).

5. We thank The Chicago Board of Trade, Mark Harabuda, and Robert Daigler for the data used in this study. The CBOT discontinued the LDB data after 2006. Further research using the data beyond 2006 would be interesting if data become available.

6. All public limit orders provide liquidity in the electronic futures markets. As a result, market makers' buy and sell prices (and hence, their effective BASs) are affected by volume and volatility that influence on all limit orders. Moreover, unlike the stock market makers, the electronic market makers in the futures markets are not bound to post bid and ask quotes (Laux and Senchak, 1992; Raman et al., 2014). Therefore, market maker's effective BAS is not included as a determinant of volume and volatility in (9-2) and (9-3), respectively. Wang and Yau (2000) use the open-out cry pit futures data from 1990 to 1994 and estimate the realized BAS by the mean of market price reversals. However, the futures prices that they have used were determined by all trader types. Hence, their estimates of BAS were not the market maker's BAS but rather that of all types of traders. Therefore, they could run a simultaneous framework to model bid-ask spread (BAS), volume and volatility. However, our study uses only the (unobserved) market maker's effective bidask spread, which does not allow such simultaneous framework.

7. One of assumptions for OLS estimation is zero covariance between regressors and residuals: $Y=a_{0}+$ $a_{1} X_{1}+a_{2} X_{2}+e$ with $\operatorname{Cov}\left(X_{1}, e\right)=\operatorname{Cov}\left(X_{2}, e\right)=0$. To examine if the values of regressor $X_{2}$ and residuals $e$ are correlated, the instrumental variables (IVs) are used to fit the values of the regressor. Let $\hat{v}$ be the residuals from the IV regression: $X_{2}=b_{0}+b_{1} I V+v$. To test endogeneity of $X_{2}$, the regressor residual $\hat{v}$ is included in the main regression equation: $Y=c_{1} X_{1}+c_{2} X_{2}+c_{3} \hat{v}+u$. If the coefficient $c_{3}$ of $\hat{v}$ is statistically significant, then the regressor $X_{2}$ is endogenous, and 2SLS estimation is consistent and preferred over OLS.

8. The value of lagged variable at the first intraday interval is the value from 7:00 AM to 7:30 PM.

9. The trading volume by CTI3 traders is not included in the models due to their negligible trading volume shares. Inclusion of their volume in the model does not alter the results.

10. Only the main regression equations about market makers' half bid spread (BS) and half ask spread (AS) are shown in (11) and (12) for space consideration. Each of models in (11) and (12) is simultaneously determined via 2 SLS with the equations in (10-2) to (10-5).

11. All regression models on BAS commonly include TTM (time to maturity). As expected, TTM exhibits a negative sign, meaning that BAS widens when the maturity nears, although the coefficient of TTM in the 2Year T-note futures is not statistically significant.

12. Results in models (9-3) in panels $\mathrm{a}, \mathrm{b}$ and $\mathrm{c}$ show that trading volume is high when and volatility is high $b_{31}>0$ in (9-3)). This result is consistent with Karpoff (1987) and Wang and Yao (2000).

13. The interaction term (Volume 2 x AFTER) shows all positive signs, for example, 0.14 in the model (10-1) in Panel $b$. As a result, the negativity of the coefficient of Volume2 is reduced after the reclassification of nonclearing member institutional traders from CTI4 into CTI2. That is, the coefficient of Volume 2 in year 2005 and 2006 is about $-0.50+0.14(=-0.36)$ in the model $(10-1)$. The results represent that the trading patterns of non-clearing member traders are similar to those of the CTI4 traders (Cho et al., 2019).

14. One exception is that the market makers in the 2-Year T-Notes futures market do not exhibit pronounced contrarian trading patterns.

15. The interaction terms, BUY2 $x$ AFTER and SELL2 $x$ AFTER exhibit the effects of reduction in the overall trading pattern of the CTI2 traders. That is, for the 5-year T-note futures the expected signs in regression coefficients are satisfied for the CTI2 traders i.e., $|-0.74|>|0.45|$ on the BS in model (11) of Table 5 before 2005. The expectation remains consistently satisfied since 2005 in that $|-0.74-0.08|>|0.45+0.23|$. But, the extent of inequality has diminished since the size difference between $|-0.74-0.08|$ and $|0.45+0.23|$ is smaller than that between $|-0.74|$ and $|0.45|$. The qualitatively same results appear for the 2-Year and 10-Year T-note futures.

16. Estimation results in Table 5 stay qualitatively unchanged when we included the first deferred contracts in the sample when the nearby contracts become inactive. One exception is that the 10-Year T-notes lose statistically significance. 


\section{REFERENCES}

Amihud, Y., \& Mendelson, H. (1980). Dealership market: Market-making with inventory. Journal of Financial Economics, 8(1), 31-53.

Avramov, D., Chordia, T., \& Goyal, A. (2006). The impact of trades on daily volatility. Review of Financial Studies, 19(4), 1241-1277.

Bagehot, W. (1971). The Only Game in Town. Financial Analysts Journal, 27(2), 12-14, 22.

Bekaert, G., \& Wu, G. (2000). Asymmetric Volatility and Risk in Equity Markets. Review of Financial Studies, 13(1), 1-42.

Cheng, K., Fung, J., \& Tse, Y. (2005). How electronic trading affects bid-ask spreads and arbitrage efficiency between index futures and options. Journal of Futures Markets, 25(4), 375-398.

Cho, J.H., Daigler, R., Ki, Y., \& Zaima, J. (2019). Destabilizing momentum trading and counterbalancing contrarian strategy by large trader groups. Review of Accounting and Finance, 19(1).

Chou, K., Wang, K., \& Wang, Y. (2015). The impacts of individual day trading strategies on market liquidity and volatility: Evidence from the Taiwan index futures market. Journal of Futures Markets, 35(5), 399-425.

Chung, K.H., Van Ness, B.F., \& Van Ness, R.A. (1999). Limit orders and the bid-ask spread. Journal of Financial Economics, 53(2), 255-287.

Copeland, T.E., \& Galai, D. (1983). Information Effects on the Bid-Ask Spread. Journal of Finance, 38(5), 1457-1469.

Daigler, T., \& Wiley, M. (1999). The impact of trader type on the futures volatility-volume relation. Journal of Finance, 54(6), 2297-2316.

Demsetz, H. (1968). The cost of transacting. Quarterly Journal of Economics, 82(1), 33-53.

Ding, D.K. (1999). The Determinants of Bid-Ask Spreads in the Foreign Exchange Futures Market: A Microstructure Analysis. Journal of Futures Markets, 19(3), 307-324.

Easley, D., \& O'Hara, M. (1987). Price, trade size, and information in securities markets. Journal of Financial Economics, 19(1), 69-90.

Frank, F., \& Garcia, P. (2011). Bid-Ask Spreads, Volume, and Volatility: Evidence from Livestock Markets. American Journal of Agricultural Economics, 93(1), 209-225.

French, K., \& Roll, R. (1986). Stock return variances: The arrival of information and the reaction of traders. Journal of Financial Economics, 17(1) 5-26.

Glosten, L.R., \& Milgrom, P.R. (1985). Bid, ask and transaction prices in a specialist market with heterogeneously informed traders. Journal of Financial Economics, 14(1), 71-100.

Glosten, L.R., Jagannathan, R., \& Runkle, D.E. (1993). On the Relation between the Expected Value and the Volatility of the Nominal Excess Return on Stocks. Journal of Finance, 48(5), 1779-1801.

Harris, L. (2003). Trading and Exchanges: Market Microstructure for Practitioners. New York: Oxford University Press.

Harris, M., \& Raviv, A. (1993). Differences of Opinion Make a Horse Race. Review of Financial Studies, 6(3), 473-506.

Hasbrouck, J. (1988). Trades, quotes, inventories and information. Journal of Financial Economics, 22(2), 229-252.

Huang, R.D., \& Stoll, H.R. (1997). The Components of the Bid-Ask Spread: A General Approach. Review of Financial Studies, 10(4), 995-1034.

Karpoff, J.M. (1987). The Relation Between Price Changes and Trading Volume: A Survey. Journal of Financial and Quantitative Analysis, 22(1), 109-126.

Laux, P.A., \& Senchack, A.J. (1992). Bid-Ask Spreads in Financial Futures. Journal of Futures Markets, $12(6), 621-634$.

Lee, C.M., Mucklow, B., \& Ready, M.J. (1993). Spreads, Depths, and the Impact of Earnings Information: An Intraday Analysis. Review of Financial Studies, 6(2), 345-374.

Llorente, G., \& Wang, J. (2020). Trading and information in futures markets. Journal of Futures Markets, $40(8), 1231-1263$. 
Massimb, M.N., \& Phelps, B.D. (1994). Electronic trading, market structure and liquidity. Financial Analyst Journal, 50(1), 39-50.

McInish, T.H., \& Wood, R.A. (1992). An Analysis of Intraday Patterns in Bid/Ask Spreads for NYSE Stocks. Journal of Finance, 47(2), 753-764.

Raman, V., Robe, M.A., \& Yadav, P.K. (2014). Electronic Market Makers, Trader Anonymity and Market Fragility. SSRN. Retrieved from https://ssrn.com/abstract=2445223

Schwartz, R.A. (1988). Equity Markets. New York: Harper and Row.

Stoll, H.R. (1978). The Supply of Dealer Services in Securities Markets. Journal of Finance, 33(4), $1133-51$.

Tinic, S.M. (1972). The Economics of Liquidity Services. Quarterly Journal of Economics, 86(1), 79-93.

Wang, G.H., \& Yau, J. (2000). Trading Volume, Bid-Ask Spread, and Price Volatility in Futures Markets. Journal of Futures Markets, 20(10), 943-970.

Wang, G.H., Michalski, R.J., Jordan, J.V., \& Moriarty, E.J. (1994). An Intraday Analysis of Bid-Ask Spreads and Price Volatility in the S\&P 500 Index Futures Market. The Journal of Futures Market, 14(7), 837-859.

\section{APPENDIX}

\section{Volume Weighted Average Price}

This appendix describes the market maker's effective bid-ask spread using the volume weighted average price (VWAP) as in Harris (2003, pp. 424-426). The volume weighted average price (VWAP) is the most common benchmark price in estimating transaction costs. The VWAP is defined as the price level at which the weighted average transaction is made. Hence, traders like the VWAP benchmark because they would like to trade at least as well as the average trader. Specifically,

$V W A P_{i t}=\sum_{j} v_{j i t} P_{j i t}$

where $v_{j i t}=\frac{T S_{j i t}}{\sum_{j} T S_{j i t}}$ with $T S_{j i t}=B U Y_{j i t}+S E L L_{j i t}$

where $j$ stands for the index for price at which trades have occurred. The subscripts $i$ and $t$ represent the indexes for intraday dummy $(i=1, \ldots, 13)$ and day $(t=1, \ldots, T) . T S_{j i t}$ and $v_{j i t}$ are the trade size and volume weight, respectively, at price $P_{j i t}$. Market makers' buy and sell prices for an intraday period of $i$ are similarly determined as follows.

Buy price $_{i t}=\sum_{j} b_{j i t} P_{j i t}$, where $b_{j i t}=\frac{B U Y 1_{j i t}}{\sum_{j} B U Y 1_{j i t}}$

Sell price it $=\sum_{j} S_{j i t} P_{j i t}$, where $s_{j i t}=\frac{S E L L 1_{j i t}}{\sum_{j} S E L L 1_{j i t}}$

where $B U Y 1_{j i t}$ and $S E L L 1_{j i t}$ are the buy and sell volumes of market makers (CTI1) at $j, i$ and $t$. If buy and sell volumes by the CTI2 and CTI4 traders are used, then their volume-weighted average buy and sell prices are determined as done in (A2) and (A3). Based on (A1), (A2) and (A3), the bid, ask and bid-ask spreads are determined as shown in (3), (4) and (5), respectively.

\section{Robustness of Results}

We report the results of robustness analyses in Appendix for space consideration. Detailed statistical results are available upon requests.

Earlier, we demonstrated in Table 3 that market makers may experience losses by realizing negative bid-ask spreads caused by high price volatility. When the market makers successfully make the market by protecting against risk, their buy prices are lower than sell prices, which results in positive BASs. Hence, 
the hypotheses $\mathrm{H} 1$ and $\mathrm{H} 2$ test results reported in Tables 4 and 5 are obtained using data sample that contains only positive BAS. In the robustness analysis, we run same battery of tests using full data sample that includes both negative and positive BASs.

The results of robustness tests are as follows. First, the values of coefficients on Volatility decrease. As shown in Table 3, this is caused by the fact that the BAS takes either negative or positive values depending on the success of market making when volatility increases. However, even using the full data sample we see that the coefficient of Volatility remains positive, since market makers react to risk by widening the BAS in general when volatility rises.

Second, using the full sample, we confirm that the market makers narrow the BAS in response to increased trading volume of CTI1 and CTI2 traders, but widen the BAS when the CTI4 traders increase trading volume.

Third, qualitatively similar results appear in the model (11) estimated for 5-Year and 10-Year T-note futures. It is noticeable that the market makers' bid spreads (BSs) are more sensitive to the CTI4's sell trades rather than buy trades not only in the absolute size of the coefficients but also in statistical significance. This finding holds across all analyzed futures maturities. The market makers' sensitivity in protecting against risk when they sell and the CTI4 traders buy remains statistically significant only for the 2-Year T-note futures in model (12). Prior studies document that volatility is asymmetric, in that it is larger when sell trades dominate and prices fall (Glosten et al., 1993; Bekaert and Wu, 2000; Avramov et al., 2006). Overall, robustness checks demonstrate that our findings hold even if we use a full data sample. 